\title{
Inclusive Fitness Theory and the Evolution of Mind and Language
}

\author{
Harry Smit ${ }^{1}$
}

Received: 4 January 2016/Accepted: 16 March 2017/Published online: 23 March 2017

(C) The Author(s) 2017. This article is an open access publication

\begin{abstract}
Philosophers have shown that the Aristotelian conception of mind and body (monism) is capable of resolving the problems confronting dualism. In this paper the resolution of the mind-body problem is extended with a scientific solution by integrating the (neo) Aristotelian framework with evolutionary theory. It is discussed how the theories of Fisher and Hamilton (two extensions of Darwin's theory) enable us to construct and solve hypotheses about how the mind evolved out of matter. These hypotheses are illustrated by two examples: the evolutionary transition from cells to multicellular organisms (with internal and external organs), and the evolutionary transition from babbling to doing things with words and later reasoning and giving reasons. The first transitions resulted in the sensitive psyche of the other animals, the second in the rational psyche of humans. It is discussed how exploratory behaviour of lower-level entities facilitated these evolutionary transitions.
\end{abstract}

\section{Introduction}

The mind-body problem is a philosophical problem. It has been resolved as the result of investigations of Hacker, Kenny, Ryle, Wittgenstein and others. They have shown that elaborations of Aristotle's conception of the mind and body (monism) are capable of answering the questions confronting Plato's, Augustine's and Descartes' dualism. However, their arguments will not be repeated here; I shall only briefly discuss why contemporary, essentially Cartesian, conceptions of conscious experiences are highly problematic (Sect. 2) and elaborate some essential

Harry Smit

h.smit@maastrichtuniversity.nl

1 Department of Cognitive Neuroscience, Faculty of Psychology and Neuroscience, Maastricht University, P.O. Box 616, 6200 MD Maastricht, The Netherlands 
differences between Cartesian dualism and Aristotelian monism (Sect. 3). What I shall discuss instead is how we can reconcile the resolution of the mind-body problem [what Hacker (2007) has called the neo-Aristotelian conception of mind and body] with scientific insights. I restrict my discussion to the problem of how we can integrate the neo-Aristotelian conception with evolutionary theory. There is a simple reason: if we can reconcile the neo-Aristotelian conception with evolutionary theory, then we must be able to construct testable hypotheses about how the mind or psyche evolved out of matter. And if we have shown that we can solve some empirical problems with the aid of the newly constructed conceptual framework, the resolution is extended with a solution of the mind-body problem.

The integration of the neo-Aristotelian conception of the mind with evolutionary theory requires a correct interpretation of Darwin's contribution. The point to notice is that many philosophers and scientists have mistakenly argued that Darwin replaced the argument from design (of natural theology) by explanations in terms of natural selection, while a few correctly argued that Darwin returned to Aristotelian teleology, eliminated the concept of design, and extended the Aristotelian framework with evolutionary explanations (see Hacker 2007; chapter, 6; Kenny 1988; Smit 2010a, 2014). Notice that the incorrect interpretation was taken to imply that Darwin extended mechanistic (proximate) with evolutionary (ultimate) explanations. That Darwin's contribution was misinterpreted is one reason why it appeared to many that the mind-body problem was hard to solve, because they investigated the problem within the confines of a misguided Cartesian-Darwinian conceptual framework.

I shall discuss in this paper two extensions of Darwin's theory that enable us to form testable hypotheses, namely those made by the evolutionary theorists Fisher and Hamilton (Sects. 5, 6 and 7). Interestingly, their insights are also conceptual or philosophical insights. I argue that we can apprehend their contributions if we discuss their ideas against the background of Wittgenstein's discussion of measurement in the natural and mental sciences (Sect. 4). For this enables us to see how the ideas of Fisher and Hamilton clarify a conceptual observation made by Wittgenstein and others, namely that we attribute mental predicates to the whole, behaving organism, not to its parts. This was later called by Hacker a mereological principle. Understanding the connection between the mereological principle and the ideas of Fisher and Hamilton, and how we can extend their ideas with facilitated evolution and language evolution (Sects. 8 and 9), enables us to conclude that, in principle, the mind-body problem is solved. In a Kuhnian terminology: the new conceptual framework enables us to construct and solve 'puzzles'.

\section{The Contemporary Conception of the Mind}

The contemporary conception argues that conscious experience is the central feature of the mind. It is developed as a response to central state materialism (which identifies types of mental states with types of brain states) and functionalism (which attempts to explain the nature of a mental state by reference to its function in correlating inputs, behavioural outputs and its causal relations to other mental 
states). Since internal mental states are according to materialism and functionalism defined solely in terms of brain states or functional terms, critics argued that something was missing, namely the felt character of the experiences that sentient creatures enjoy, such as experiences of pain, pleasure, being sad, longing, etc. The critics made for this reason a contrast between humans (and the other animals) and creatures who are subject to the same inputs and behavioural outputs, but who do not enjoy these conscious experiences (called 'zombies'). This contrast raises the question what these conscious experiences are (and what their evolutionary advantages are, etc.).

The conscious experiences are thought to be something essentially subjective and underlie behaviour. The behaviour that exhibits mental phenomena is merely the outer husk of the inner psychological reality with which the subject is acquainted. Notice that this conception of experiences runs parallel to the Cartesian conception, for Descartes also held that perceptual experience, imagination, cogitation, affection and volition constitute the domain of consciousness. What was new was how conscious experiences were characterized. An experience was said to be conscious if there is something which it is like for the subject to have it (Nagel 1974; see also Chalmers 1996). That was thought to be the essence of consciousness.

Each conscious experience is argued to have its own qualitative character or its distinctive phenomenal feel (qualia for short). The individual feel of an experience is called a quale, signifying the 'qualitative character of experience'. The subjective or qualitative feel, following Nagel, can be characterized in terms of there being 'something it is like' for an organism to have the experience. A subject of experience is conscious if there is something that it is like for it to be that subject. For while there is nothing which it is like for a machine to be a machine, there is something it is like for a bat to be a bat, for us to be human, etc. However these ideas are confronted by many problems (see Hacker 2002; Bennett and Hacker 2003, chapters 10 and 11). I shall mention only two of them.

First, it is left unexplained what is meant by the claim that 'there is something which it is like to have a given conscious experience'. Defenders of the claim argue that every experience has a qualitative character. But they apparently confuse here the quality of what one experiences (the taste of an apple) with the quality of the experience (delightful). For the perceptual quality is not a quality of a perception (an experience). The taste of an apple is not a quality of tasting it, but a quality of what one tastes.

Second, an answer to the question 'What was it like for you to have an experience' is a request for a description of the felt character of the experience. Hence one may answer by saying: 'It was delightful'. But this answer does not allow one to conclude that there was something that it was like for $\mathrm{N}$ or for me to experience E. For the experience was not like delightful; it was delightful. Of course, it makes sense in certain contexts to ask what it is like to be for example a soldier, or what it is like for a woman to be a soldier. But these questions are a request for a description of the pros and cons of a certain role (or of the various things we do). It demands a specification of the qualitative character of the life a soldier, of the typical career of a soldier, or what it is like for a woman, as opposed to a man, to be a soldier. But notice that in all descriptions the 'like' drops out in the 
replies. Notice further that we can licitly ask what it is like for a woman to be a soldier, but not what it is like for a soldier to be a soldier, or for a human being to be a human being, for a bat to be a bat (the questions that Nagel poses).

What is true is that only conscious, sentient creatures are subjects of experience and can find them pleasant or unpleasant, interesting or boring, and so forth. But the question 'What is it like for a human being to be a human being' (or for a bat to be a bat) is illicit. This is not asking what is it like for an $\mathrm{X}$ to be a $\mathrm{Y}$, for this question reiterates the subject term in the object position and has the form 'What it is like for an $\mathrm{X}$ to be an X?'. If any sense can be made of the question 'What is it like for a human being to be a human being?', it amounts to no more than 'What is human life like?'. So too the question 'What is it like for a bat to be a bat?' amounts to no more than 'What is the life of a bat like?' It is given by describing their foraging behaviour, how they communicate, etc. Hence we can simply consult here studies of zoologists (i.e. behavioural ecologists; see Davies et al. 2012).

It is important to note that this conclusion does not imply that we return to a form of behaviourism. For we are not denying that human beings, like all other sentient creatures, have experiences. Behaviourism has some merits but also faults. Its merits were to emphasize that language learning is based on training. This presupposes shared behavioural reactions and responses. Behaviourists were also right to emphasize that acquiring a language is learning new forms of behaviour: children learn to do things with words in human interactions (they do not learn to translate a 'Language of Thought' (LoT) into words and sentences as Pinker (1995) and others assume, ${ }^{1}$ for there is no such thing as a LoT (see further Smit 2016)). Logical behaviourists were also right to highlight that the criteria for attributing mental predicates to other people are behavioural (what they do and say). But they were mistaken in conceiving the relationship between the mental attributes and behaviour reductively (they supposed that the mental is reducible to the behavioural). Yet the relationships between behavioural and linguistic expressions of the mental are internal or conceptual: expression constitutes criteria, constitutive evidence, for ascribing psychological predicates to humans and other animals. The point to notice that the criterial link is not external or inductive; the behaviour displayed is normally sufficient to ascribe a psychological attribute to another being, but it is defeasible. For example the relation between behavioural and linguistic expressions of an emotion and the emotion is not like the relation between a natural sign (clouds or smoke) of something and what it is a sign of (rain or fire). It is the relation between a form and what it is a form of (White 1967, p. 118f.). Clouds may occur without rain, and someone may tremble without fear. We can also conceal or pretend an emotion (pretending is not a manifestation of an emotion; it merely looks like it because one mimics an emotion which one does not feel). These are all examples of a defeasible evidential relationship. But there is an important

\footnotetext{
${ }^{1}$ Pinker (1995, p. 81) argues that: 'People don't think in English or Chinese or Apache; they think in a language of thought'. Knowing a language is according to him (p. 82) knowing 'how to translate this language of thought (or mentalese) into strings of words and vice versa ... Indeed, if babies did not have a mentalese to translate to and from English, it is not clear how learning English could take place, or even what learning English would mean'. For an apt critical discussion of Chomsky's and Pinker's ideas, see Hacker (1990b) and Evans (2014).
} 
difference: the relation between rain and a cloud, and between smoke and fire, is external (inductive), whereas the relation between an emotional expression and what it is an emotion of is not. We see e.g., the fear, anger or shame in someone's face. The facial expressions are not signs of the emotions, but manifestations: they make the emotion patent. Hence we do not infer an emotion when someone turns red or deduce one when he or she blushes (by contrast: clouds do not manifest rain and smoke does not express fire ${ }^{2}$ ). Behavioural manifestations are not effects of the emotion, but the forms they take. Unsurprisingly, we sometimes misinterpret what we observe, for there are subtle differences between manifestations of emotions, for example when we listen to someone it may sound like affection but was no more than courtesy (notice that this argument does not apply to innate expressions of emotions).

\section{The Neo-Aristotelian and Cartesian Conception of the Mind}

I discuss in this section briefly two essential differences between Cartesian dualism and neo-Aristotelian monism (see Hacker 2007, chapters 8, 9 and 10; Kenny 1989, chapters 1, 2 and 3).

First, according to Aristotle there is only one world, while Descartes distinguished two worlds, namely the physical world containing matter, energy and all the tangible bodies (including the human body and its brain), and the psychical world consisting of mental events, processes and states which are inaccessible to public observation. Although Descartes distinguished two separate worlds, he left in his dualism space for a mysterious interaction between these two worlds. The mind is according to Descartes united to the pineal gland (what we now call the pineal body).

The Cartesian distinction between the two worlds leads to an unresolvable problem: how can we measure the mind? For the res cognitans, in contrast to the res extensa, does not consist of matter in extension. As the evolutionary biologist Williams (1985, p. 22) put it: 'the power of positive thinking has never been measured in calories per second, nor a burden of grief in grams'. And if we cannot measure one of the two substances involved, we also cannot answer the question of how the mind is related to (or interacts with) the body or brain. The neo-Aristotelian conception resolves this Cartesian problem in a simple way: Aristotle argued correctly that there is no relation between the mental and the physical, between mind and body (or brain). The mind is manifest or expressed in behaviour, but an expression does not mean that there are mysterious mental processes occurring in a separated realm behind the observable behavioural and linguistic expressions of the mental (see further Sect. 4). Neo-Aristotelians, living in a post-Darwinian era, add that we can observe and measure the expressions by investigating the different

\footnotetext{
${ }^{2}$ Of course, 'Here lions threat, there elephants will range, and camel-necks to vapoury dragons change...'. But this line, taken from a poem of Goethe about clouds, only shows that clouds, by taking temporarily certain physical appearances, look like animals.
} 
forms of expressive behaviour and how these evolved during the course of evolution.

Second, Descartes' distinction between the two worlds is linked to his distinction between humans and the other animals and differs therefore from Aristotle's distinction. According to Descartes only humans possess a mind, whereas the other animals are mere machines. Aristotle, by contrast, argued that humans are not minds united to a machine, but living organisms, i.e. living bodies of a certain kind. He characterized human beings as distinct from other animals and plants by observing what they can do. According to him, the psyche informs a natural body that has life and this is visible in the exercise of capacities. And since the psyche is ascribed to living organisms, the capacities that constitute the psyche cease to exist when the living animal dies. In Descartes' dualism, by contrast, the mind is not the form of the living body that has life, but a separate, immaterial substance.

Aristotle ascribed the psyche to the (whole) living organism. He argued that not only humans but also plants and the other animals possess a psyche. Plants possess a vegetative and the other animals on top of that possess a sensitive psyche. Humans are unique because they possess a rational psyche (the rational powers of the intellect and the will), for, neo-Aristotelians argue, only humans use a language. The use of a language enables humans, in contrast to the other animals, to possess objective and abstract information which they can use to reason, to freely pursue goals formulated by the intellect, and to make decisions. But how do children acquire the ability to reason and think? Neo-Aristotelians argue that children learn to reason and think when they learn to transform expressions according to a paradigm. For example when we explain to children that lions are carnivores and ask them what Simba, a lion, will prefer (a piece of meat or an apple?), we teach them what an inference is (what correct answers are). The point to notice is that rules of inference do not follow from the meaning of the logical constants and quantifiers involved in inferences, but are constitutive of the meaning of logical constants and quantifiers. Hence if we explain to a child by means of concrete examples that $(f a)$ follows from $(x) f x$ we give an explanation of what the universal quantifier means and teach him or her the technique of inferring (reasoning, thinking). Note that the neo-Aristotelian conception of how children acquire the ability to reason and think presupposes that children have already mastered some rules for the use of words and sentences. Hence the ability to reason evolves out of the ability to combine words and probably evolved during the course of evolution for similar reasons (humans did not as the result of a mysterious macro-mutation suddenly started to reason and think; see further Smit 2016).

Humans, as language-using creatures, become according to neo-Aristotelians autonomous creatures when they can pursue self-selected goals that go beyond the immediate environment in space and time. Animals, having a sensitive psyche, can also pursue goals, but these are to a large extent restricted to the here and now. NeoAristotelians emphasize that only a creature that has mastered rules for the use of symbols and signs can pursue goals beyond the temporal and spatial present. Consequently only in humans both the operations of the senses and the will are suffused with (abstract) conceptualizations of the intellect. We are not only (at least partially) in control of our desires and wants, but can pursue (abstract) goals and 
ideals (we can form rational desires). This also clarifies why only humans use tools that require the mastery of concepts. The use of a clock is an example, for it requires an understanding of the concept of time, but the use of a stick to collect termites is not an example, for it does not require the use of a concept. Animals can discriminate between colours, have food preferences, have pain, et cetera. Human children acquire on top of that the concept of colour, taste, and pain. We, as language-using creatures, have an intellect enabling us to subsume what we see under universal concepts, can make objective judgments about what we see with the aid of these concepts, and can understand the differences between empirical judgments ('This rose is pink') and grammatical judgments ('Red is darker than pink'). Yet these typical linguistic abilities are of course connected to how we act and take action, for, as I shall later explain, they evolved as an extension and replacement of the conative behaviours which were already present in our ancestors.

\section{Mental Sciences are Not a Young Science}

The insight that (neo) Aristotelian monism is a serious alternative to Cartesian dualism set the stage for the definitive (re) solution of the mind-body problem. An important step toward its further resolution was taken by Wittgenstein in his Philosophical Investigations. He realized that its resolution requires conceptual investigations of how we can measure mental phenomena. If we do not realize that there are conceptual problems involved, we will mistakenly believe that the problem is an empirical problem requiring only further empirical studies. Wittgenstein (2009 [1953], Philosophy of Psychology_A Fragment, par. 371) argued that:

The confusion and bareness of psychology is not to be explained by calling it a 'young science'; its state is not to be compared with that of physics, for instance, in its beginnings. (...). For in psychology there are experimental methods and conceptual confusion. (...).

The existence of the experimental method makes us think that we have the means of solving the problems which trouble us; though problem and method pass one another by.

This remark was directed at the Gestalt psychologist Köhler who had argued that the situation in the mental sciences (psychology; nowadays we can add here cognitive neuroscience) is comparable to the situation physics was in when it was a young science. Physics developed according to Köhler from a young into a mature science as the result of transformation of qualitative observation into quantitative measurement by means of sophisticated techniques and instruments. For example observations of thermal properties (warm, cold) were replaced by indirect quantitative measurement of temperature (changes in the state of, for example, water as the result of changes in kinetic energy are used to measure changes in temperature). Hence when physics developed into a mature science, qualitative observation was progressively replaced by indirect quantitative measurement. These new instruments facilitated the discovery of precise functional laws (for instance in thermodynamics; see further below). Köhler (1947, p. 42.) argued that: 
If we wish to imitate the physical sciences, we must not imitate them in their contemporary, most developed form; we must imitate them in their historical youth, when their state of development was comparable to our own at the present state.

Wittgenstein objected to this idea. The problems confronting the mental sciences are according to him not solved by replacing the qualitative descriptions (in terms of our ordinary psychological vocabulary) by indirect quantitative descriptions in a neurophysiological terminology (see Hacker 1996, chapter 5). He argued that the development of quantitative methods and instruments in the mental sciences (for example galvanographic or pneumographic methods or more modern methods such as fMRI or ERP) does not result, as in physics, in the development of a mature science out of a young one. For it was according to him a cardinal mistake that Köhler called psychology a young science comparable to physics in its early period. While we can in physics replace thermal concepts (hot, warm, etc.) by concepts of temperature for the purposes of physics, we cannot in a similar way eliminate mental concepts (like believing that $p$, fearing that $q$, or intending to $V$ ) from statements of psychological generalization and replace them by neurophysiological concepts. 'Seeing, hearing, thinking, feeling, willing, are not the subject of psychology in the same sense as that in which the movements of bodies, the phenomena of electricity etc., are the subject of physics (Wittgenstein 2009 [1953], par. 571). The reason is that mental phenomena are not hidden behind the (observable) behaviours and linguistic expressions of the subject (see Hacker 1990a; Malcolm 1986). By contrast: there are hidden collisions of molecules behind (our observation of) an increase of temperature of a gas, just like there is a movement of an electron behind the trace we observe in a Wilson cloud-chamber. The essential point to notice is that the mental domain, in contrast to the physical domain, is not populated with (hidden) mental objects, events, states or processes. The mental, following the neo-Aristotelian conception, is manifest or expressed in behaviour and is therefore directly observable. And the expressions of the mental have an essential role in human communication. They are therefore the very explananda of the science of the mental.

It is important to notice that the neo-Aristotelian conception does not exclude the possibility that some behaviours are explicable in terms of a biological cause. But neo-Aristotelians argue that we can and must differentiate causes of behaviour from reasons. Suppose I am thirsty or hungry and am seeking the satisfaction of my thirst or hunger. There may then be a biological cause for my simple conative behaviour, namely serum osmolarity in the case of thirst or a hormonal cause (changing levels of e.g. leptin or ghrelin) in the case of hunger because these hormones affect my brain. Hence in these cases it is conceivable that we can extend and in part replace our ordinary explanations (based on observing the behavioural and linguistic expressions of the sensations) with an explanation involving a biological cause. But suppose that I prepare for my wedding, am late, and rush to my car in order to pick up the flowers that I ordered a few minutes before with my mobile phone, then it is less easy to see how my volitional, goal-directed behaviour can be made intelligible by a biological cause (a well-functioning endocrine, neuro-endocrine and nervous 
system is here not a cause but a causal condition enabling me to act in this situation). The point to notice is that we make our behaviour intelligible in terms of goals and reasons. For instance when someone, observing my behaviour when I am sprinting to my car, asks me: 'Why do you ...', I will answer by saying: 'Because I ...' (and not by explaining the causal conditions enabling me to act, namely by saying that neurons in my prefrontal cortex are firing). Note that the reasons one gives for one's actions are warrants, not causes. At the proximate level it is therefore far from clear if and how we can extend (let alone replace) explanations of acts in terms of reasons by explanation in terms of (proximate) causes, for to take action or to perform a deed is to act voluntarily in response to a circumstance or in pursuit of a goal, given that the actor is capable of apprehending an opportunity and can opt for or choose one course of action over another and is not acting under duress. Humans have developed manifold forms of explanations of action in terms of goals and reasons in which causal accounts do not play a role (for a survey, see Hacker 2007, chapter 5). Apparently, an evolutionary theorist will add, there has been selection in favour of making behaviour intelligible in teleological terms since this improved human communication and cooperation and, perhaps, enhanced therefore the inclusive fitness of individuals living in human groups or societies. But even if we are not inclined or willing to use an evolutionary explanation here and prefer a cultural or historical explanation, we still have to note that this practise (the use of teleological explanations of human actions for the purpose of making actions intelligible to each other) has emerged during our (evolutionary) history.

Language evolution freed humans from the constraints imposed by genetic evolution, for it enabled us to reason and to give reasons. But since language evolved out of animal forms of communication, we can assume that at least the early stages of language evolution are explicable in evolutionary terms. Hence the early forms of linguistic behaviour were probably shaped by genetic evolution. This raises the problem of how can we investigate the development of advanced forms of linguistic behaviour (reasoning, giving reasons) out of simple forms of linguistic behaviour. It is important to distinguish two aspects.

First, young children cannot reason or give reasons for their actions. Yet when they have mastered the first use of some words, they are able to perform acts like calling, asking and answering, or expressing wants and responding to wants of others. These linguistic acts and responses are moves in (simple) language games (doing things with words enables children to engage in social interactions). Notice that these games are no longer biological games, i.e. the social interactions between animals (involving signals like the bared teeth-display of dogs) that are studied by evolutionary theorists with the aid of game theory (for instance the Hawk-Dove model). Nowadays, these simple language games are extended by complex ones culminating in the ability to engage in complex social interactions involving reasoning and giving reasons. But this developmental pattern (from doing things with words to reasoning and giving reasons) evolved during our (evolutionary) history. In Aristotelian terms: the rational psyche evolved out of the sensitive psyche when humans became sensitive to reasons for acting and responding. Hence we have to explain if and how evolutionary or ultimate explanations are capable of 
answering the question of how the (human) rational psyche gradually evolved out of the (animal) sensitive psyche.

Second, it is important to note that the development of the rational psyche required teaching and learning, for the use of a language is a rule-governed activity. Humans are unique for a biological reason: only in humans an innate ability evolved to learn the rule-governed use of a language. But learning a language is also a unique human capacity since the use of language involves the correct and incorrect applications of rules. Learning the use of language was therefore linked to the evolution of asymmetric roles in the family or group: the pupil had to understand that the teacher is the one who is explaining something, whereas the teacher had to check whether the pupil understood what was explained (Csibra and Gergely 2006, 2009). Recall that for example young chimpanzees learn to use tools (how to fish termites with sticks) by imitation, not as the result of socially guided learning.

\section{Thermodynamics}

I mentioned above, while discussing Wittgenstein's critique of Köhler's ideas, that physics developed from a young into a mature science as the result of transformation of qualitative observation ('I feel that the fire is hot') into quantitative measurement by means of sophisticated techniques and instruments. To understand Fisher's contribution to the solution of the mind-body problem (next section), it is helpful to return to the question of how observation of thermal properties (warm, cold) were in physics replaced by quantitative, indirect measurement of temperature.

Recall that the thermometer is a device that measures changes in the temperature of a system as the result of changes in kinetic energy. And recall that for example the volume of a gas in a thermodynamic system, at constant pressure, increases proportionally to changes in temperature. In theory, the volume of a sample of gas can therefore be used to measure temperature (theoretically, this can be derived from the ideal gas law $P V=n R T$ ). The point to notice is that we measure (or observe) then a macroscopic property or parameter of the whole thermodynamic system (other properties are internal energy, entropy and pressure) that defines its state. A thermodynamic system can be further characterized by the walls that delimit the system and by its connections with its surroundings (for example by tiny pores in the wall through which molecules can pass, or, in the case of the membrane surrounding a cell, by its receptors and ion channels).

Macroscopic properties are distinguished from microscopic phenomena. We can understand and study the macroscopic properties of the system without paying attention to the (microscopic) movements, velocities and collisions of the molecules constituting a gas or liquid (and the processes occurring at lower levels discussed by quantum mechanics). Yet thermodynamics assumes that the macroscopic behaviour of the system can be explained in terms of the microscopic behaviour of the very large numbers of its constituents, i.e. molecules. The velocities and collisions of the molecules determine the macroscopic properties, but since we, when we study a macroscopic property, do not know exactly at a microscopic level the simultaneous 
positions and velocities of each molecule in a gas or liquid, we need statistics for explaining the resulting thermodynamic behaviour of the whole system (its macroscopic properties). Notice that the microscopic mechanical laws concerning the position, velocity and collisions of molecules do not contain concepts such as temperature or entropy.

Thermodynamic systems discussed in physics are a thermometer, refrigerator or steam machine. In the context of the mind-body problem, it is important to notice that chemical reactions (of which we can observe the macroscopic changes in a test tube, e.g. changes in the colour or odour of a liquid ${ }^{3}$ ), cells and organisms are also thermodynamic systems. This is an important observation, as I shall later discuss in more detail, for chemical reactions are at the foot of the evolutionary tree, while cells and multicellular organisms are the branches of the evolutionary tree because they evolved out of these reactions when thermodynamic systems acquired heredity. We can reconstruct how they became branches by studying their evolutionary history at different levels of organization (phylogeny).

In both simple chemical reactions and complex organisms we can again differentiate between microscopic and macroscopic levels, yet what microscopic and macroscopic levels are depend on the evolutionary stage we investigate, for evolution resulted in a nested hierarchy of different entities. The behaviour of a cell is a macroscopic phenomenon relative to a chemical reaction, but a microscopic phenomenon relative to the behaviour of a multicellular organism. For understanding the increase in life's complexity we have to notice that there have been transitions to higher levels of organisation (for example from single cells to multicellular organisms), but also that there is one level that is involved in all major transitions. All evolutionary innovations are generated at a physical-chemical level, i.e. the level of genes. Hence there is an important difference between explaining changes in the macroscopic properties of a thermodynamic physical-chemical system and explaining changes in the traits of a living being. Only in the case of living creatures we can add an evolutionary explanation since living thermodynamic systems have acquired heredity.

There is one other distinction we have to mention. Thermodynamics distinguishes closed and open systems. An open system, like a living organism, can and does (and a closed system does not) obtain energy from the environment to (actively) maintain its internal state (for example their bodily temperature) or to maintain the stability of the whole system (of course, energy is also used for growth and reproduction). This involves metabolic pathways. Maintenance and repair are selected traits regulated by (the products of) genes. For example humans use energy for repairing damage in their body (DNA-repair by enzymes at the chemical level, but also wound healing and regeneration at the level of cells, tissues and organs). A thermometer does not use energy in this sense although chemical energy (obtained from electromagnetic waves) can alter its thermodynamic state.

Organisms can allocate energy to the systems which execute different functions in their body. This observation is the key to understanding why the soma of

\footnotetext{
${ }_{3}^{3}$ Notice that the sensitive psyche was not selected to detect microscopic changes, but, interestingly, can detect macroscopic changes in colour or odour.
} 
organisms (with a germ line-soma separation) age. It is also the ultimate explanation of the occurrence of age-related diseases of the brain (like Alzheimer's disease). Senescence is explicable in terms of the disposable soma theory, a theory deduced from the principles of thermodynamics of open systems extended with evolutionary genetics (see Kirkwood 1977). For understanding this theory we have to recall the difference between machines and living organisms. Machines do not repair damage and they deteriorate (the ultimate explanation is the second law of thermodynamics) as the result of a gradual accumulation of damage over time. There is also accumulation of damage in livings organisms, but this occurs because they put less energy in repair and maintenance. Disposable soma theory explains aging in livings organisms as the result of an accumulation of mutations in the somatic cells in our body because we allocate less energy to maintenance and repair after a certain moment in time, i.e. when most organisms in a population would have died because of extrinsic causes of mortality.

\section{Fisher's Contribution: The Evolution of Aiming and Striving}

Fisher noted that the findings of thermodynamics cannot be reconciled with the ideas of theorists, like Descartes, who argue that the fundamental laws of the universe are deterministic and believe that all systems are therefore determined by mechanical laws (Fisher 1934; see also Fisher 1950). Thermodynamics shows a disconnection between the mechanistic laws at the microscopic level (concerning the movements and velocities of molecules) and the macroscopic properties of thermodynamic systems. Fisher realized that there are interesting similarities here between evolutionary theory and thermodynamics. In both theories it is observed that aggregates (chemical reactions in a test tube, cells, or multicellular organisms) have properties that are emergent although they are the result of causal processes occurring at the level of the particles that constitute the aggregate.

The relevant example of an aggregate for understanding Fisher's contribution to the solution of the mind-body problem is the organism. It consists of cells (and its smaller constituents), but the aggregate, the whole body, has properties at the macroscopic level that are emergent but explicable as the outcome of processes occurring at lower levels. There is order and harmony at the level of the whole individual, but this order is, just like the macroscopic properties of a gas, the outcome of random processes occurring at a microscopic level.

Fisher's main contribution concerns the distinction between cause and effect and how these terms are linked to changes occurring in thermodynamic systems. Assume a cell with a membrane. Since the membrane, in contrast to a rigid cell wall, is flexible, the cell is capable of adopting different shapes (like soap bubbles). Since cells are alive, containing genes which are capable of affecting the cell's movements and interactions with other cells, we can imagine mutations having specific effects. For example, some mutations can lead to cell migration (the cell responds and moves to a chemical stimulus), other mutations can result in the 'creation' of so-called cilia enabling a cell to swim (for example a sperm cell), and yet other mutations may enable cells to engulf and eat a small cell (phagocytosis). 
Fisher highlights that mutations (originating at the microscopic level) are innovations only at the macroscopic level: mutations occur randomly as the result of physical or chemical causes at the microscopic level (there is, relative to the level of the cell, at this level randomness or indeterminacy), but these causes have creative effects at the level of the behaviour of the cell. Most of these mutations probably have disadvantageous effects, but some have advantageous effects and are then selected in the population of cells if they enhance fitness. The essential point to notice is that, according to Fisher, the creative effect has to be located in the effect of the mutation on the interaction of the (whole) cell with its environment:

The process of mutation should not properly be regarded as a cause governing the direction of evolutionary change, but only as a condition which renders evolution possible. In the same way it is probable that in relation to any effect of special interest we should never think of the casual component [e.g. of a mutation, HS] of any one particular event as by itself creative, but should recognize the creative quality as belonging only to aggregates of such casual components (Fisher 1934, p. 116).

It is in the interaction of the (whole) organism with its environment that we locate in time and place the effects of mutations resulting in evolutionary change. Following the contribution of Johannsen (1910) to genetics, we can add that selection on genotypic variation in a population, arising out of genetic mutation, occurs at the level of the phenotype.

These observations enabled Fisher to criticize the ideas of Cartesians and, important in the context of evolutionary theory, Lamarck. Cartesians (for example Laplace) assumed that the future of a mechanical system can be calculated, supposing that its initial state is known with absolute precision and that all laws of nature are given. The future state of a system, according to Cartesian determinism, does for this reason not admit a plurality of future possibilities. But this is according to Fisher problematic, for the future of a thermodynamic system which has acquired heredity does involve different possibilities. Of course, since Descartes assumed two separate realms (bodies explicable in terms of mechanics, and human beings able to act at will because only they have a mind), we can explain indeterminism in humans as the result of the free will. But this is according to Fisher not a satisfying answer, for it does not explain (and cannot explain) how willing evolved only in humans. How can Cartesians explain that only in humans a free will evolved out of 'lower animals' (our ancestors) that are essentially automata ruled by deterministic laws? The problem is that we owe our evolution 'to the same great causes which had brought the rest of the animal creation into existence' (Fisher 1934, p. 102). Thermodynamics shows according to Fisher that it is more fruitful to assume indeterminism (being a more general theory of natural causation) with determinism as a special case (only correct for certain types of objects).

Indeterminism presupposes that actions of animals (including humans) are not predetermined. The order and harmony we observe at the macroscopic level, resulting from indeterministic processes at the lower level, could have been different. Determinism, by contrast, assumes that every cause of an event is itself caused by a prior event. Consequently, if determinism ascribes to any act the full 
sense of causation, it can only be to the act of creation by which the deterministic universe was brought into existence. In this universe there is only a predetermined pattern of events which is, mysteriously, perceived by us as ordered in a time sequence running in one direction only, namely that events in the past cause future events. The problem according to Fisher is that we live in a universe in which events are not only understandable if they have a preceding cause, for we have also knowledge of the future because humans (and the other animals) are 'aiming and striving' creatures pursuing goals. For example we form intentions ('I am going to Amsterdam tomorrow') enabling us to have knowledge of future events (if I listen to someone uttering this sentence, then I can predict where he will be tomorrow) without knowledge of a preceding cause. In Descartes' universe 'aiming and striving' in animals are merely an illusion, for in Descartes' conception of the other animals' teleology does not play any role, since Descartes eliminated the Aristotelian concept of a goal (Descartes objected to Aristotle's teleology in physics, chemistry and biology (but not in the study of man), while Fisher only objected to Aristotle's use of teleology in physics and chemistry). ${ }^{4}$ The problem is that goal-directed behaviours of animals are then treated as merely illusions (for animals are according to Descartes essentially machines which can only respond). Although it appears that animals can act or refrain from acting, pursue goals and have preferences, they are according Descartes automata. Consequently, 'aiming and striving' in other animals cannot in Descartes' universe be of selective advantage, for these behaviours do not have any reality in Descartes' universe but are mere appearances. But according to Fisher's goal-directed behaviours are advantageous (1934, p. 108):

An indeterministic world, then, is one in which the human qualities of aspiration, planning and foresight, are rationally possible and may be advantageous, and in which we can recognize the primitive precursors of these qualities, not as an epiphenomenon, but as having a real part to play in the survival or death of the organisms that evince them. Biologically it might be said that purposive action by the organism as a whole is the crowning stage of an evolutionary process by which relatively large masses of living matter have come to achieve that co-operation of parts and unity of structure which we call individuality. For, on a statistical view of causation, spontaneity or creative causation is at its highest only when perfect unity is achieved.

This insight enabled Fisher to discuss an important difference between Lamarck's and Darwin's theory. Both on the Lamarckian and Darwinian theories creative causation is centered in the whole organism. The contribution of each is made effective, however, on the Lamarckian view by 'willing and striving' and on the Darwinian view by 'doing or dying'. Lamarck (1984 [1809], Part 1, chapter 7) had to assume that new (adaptive) ways of satisfying desires (arising because organisms always explore the environment and accidentally develop a new habit) evolve because these new habits have the power to induce at the microscopic level

\footnotetext{
${ }^{4}$ Notice that we can reconcile Fisher's ideas for this reason with the (neo) Aristotelian conception of the mind and body, but not with Descartes' conception.
} 
(molecules constituting our genes) heritable changes which should enable corresponding desires and efforts in the offspring to be more perfectly satisfied. But the change occurring at level of the molecules is then no longer random, but becomes the creative cause itself. This idea is mistaken for empirical reasons (see Smit 2010c), but also in contradiction with the principles of thermodynamics. In Fisher's theory changes at the level of molecules occur randomly and become creative causes because of their effects at the level of the aggregate. His theory, just as in thermodynamics, makes no assumption about the causes by which new mutations at lower levels arise. Natural selection results at the proximate level in 'willing and striving' agents, but these are at the ultimate level the outcome of a process that always begins with randomness or indeterminism. But goal-directed behaviours did evolve, for:

Consciousness and more or less intelligent mental life would seem to have played an increasing part in the adaptation of the higher animals to their surroundings, and the diversity and intricate possibilities of these surroundings seems to have provided a necessary and sufficient condition for such mental development (Fisher 1934, p. 111).

For understanding Fisher's contribution to the solution of the mind-body problem, we have to notice five features of his theory.

First, Fisher highlights the fact that the evolution of the human rational psyche is, just as the evolution of the vegetative psyche of plants and the sensitive psyche of the other animals, not an epiphenomenon. The evolution of the mind is explicable in terms of Darwin's theory if we notice that the psyche evolved out of lower-level entities that display exploratory behaviour. Moreover the mind (recall that we characterize the mind in Aristotelian terms, namely by the organism's capacities visible in the behaviour they display) has a role in the evolutionary process, for selection acts on the organism exercising its capacities. Fisher realized that, although evolutionary innovations arise at the physical-chemical level (DNA), mutations affect the behaviour of a whole organism exercising its capacities, including its mental capacities. These mental capacities are not capacities of a separate mind (as Cartesians believed) or of the brain. For example mutations may improve the ability of the whole organism to see with eyes and this improvement is visible in its behaviour. ${ }^{5}$ Notice that the behaviour of the brain may be also emergent, explicable by reference to the interactions of its parts. But the behaviour of a human being is not an emergent or supervenient property of the brain. That we see with eyes, mean something, or can use our hands to point and to write our name is not a property of the brain.

Second, Fisher's theory highlights the fact that, although organisms pursue goals, we do not need to assume a vital force for explaining how goal-directed activities

\footnotetext{
5 Eyes (or brains) cannot be said to see; it is the whole sentient being that perceives (see further Bennett and Hacker 2003; Smit and Hacker 2014). If someone has poor eyesight, his eyes do not see poorly, but he sees poorly. We say so because we observe that he, not his eyes (or his brain), has problems in finding his way around (he bumps into thing or falls over things and cannot find things by looking, etc.). Seeing or walking are predicates applicable to the whole, behaving human being using his eyes and legs, not to the parts (eyes, legs).
} 
and acts evolved. 'Aiming and striving', although they occur in living nature, are not vital forces which we can use as parts of ultimate explanations. They are evolved (proximate) goal-directed behaviours.

Third, higher level aggregates or collectives acquire as the result of evolution properties that are not present at the level of their constituents. Fisher highlights the fact that effects of random (lower-level) mutations result in the emergence of macroscopic properties since it is the whole organism that interacts with its environment.

Fourth, Fisher's theory clarifies why we attribute psychological predicates to the whole organism, not to its parts (just as we ascribe temperature to the macroscopic properties of a whole system, not to the molecules). His theory fits therefore within the conceptual framework of neo-Aristotelian monism, for Fisher's contribution clarifies why we ascribe mental predicates to the whole behaving individual (and not to a gene, a cell or an organ like the brain). That we ascribe mental predicates to the whole behaving organism is called by neo-Aristotelians a principle of mereology (Hacker 2007). It is illuminating to note that this principle also applies to computers or calculators (see Kenny 1984, chapter 10, 1989, chapter 10). We can distinguish the (microscopic) processes going on in the hardware from the outcome of a calculation (made possible by these processes). The point to notice is that the outcome is dependent on the keys (for example the multiplication or square-root key) and the output display. The calculation can be done with many different wired electronic devices (there is to a certain extent randomness at the level of the hardware), but this is not where the calculation can be located (there is no calculation going on in the hardware separated from the keys and output display). Only the whole calculator can do calculations for us. ${ }^{6}$ Hence just as Fisher emphasized that evolutionary adaptations are located in the interaction of whole organisms with the environment, Kenny noticed that calculation is located in the interaction between the whole calculator (or computer) and its users.

Fifth, Fisher's theory explains why there is direction or progress in evolution, just as there is direction in thermodynamic systems. The latter is explicable by the second law of thermodynamics, the first direction in terms of Fisher's well-known fundamental theorem of natural selection (see Fisher 1930).

\section{Hamilton's Inclusive Fitness Theory}

Fisher (1934, p. 108) made two observations. First, goal-directed behaviour displayed by an individual is the crowning stage of evolution and, second, evolution of goal-directed behaviour requires unity of the lower-level structures constituting the individual. Hamilton's contribution is an elaboration of the second observation: he developed a general theory explaining how higher level individuals evolve out of lower-level entities as the result of cooperation between lower-level entities and the

\footnotetext{
${ }^{6}$ Although strictly speaking calculators do not (cannot) calculate, any more than clocks can tell the time as opposed to showing the time. Calculators produce the results of a calculation without anyone or anything actually calculating.
} 
suppression of conflict. The result was that Fisher's analogy with thermodynamic systems was, in part, replaced by a social theory capable of explaining both cooperation and conflict.

Hamilton's theory is an actor-oriented theory (see West and Gardner 2013): it explains the changes in the fitness of an actor as the result of an interaction with a recipient. The theory has two principles for explaining cooperation (Gardner, West and Wild 2011; Hamilton 1964). Cooperation can evolve as the result of direct or indirect fitness benefit. Direct fitness benefits occur when both the actor and recipient benefit from the interaction (called mutual benefit), i.e. when the benefits are higher than the costs of the act $(B>C)$. Indirect fitness benefits occur when actor and recipient are genetically related: if the fitness of the recipient increases as the result of the action of the actor, then this fitness increase indirectly contributes to the fitness of the actor if the indirect benefits multiplied by the relation coefficient is higher than the costs of the act $(r B>C)$. This is called altruism. Notice that mutual benefit and altruism are here used as technical terms.

In order to illustrate how Hamiltonian social theory explains phenomena, I discuss how the kingdoms of plants and animals evolved out of a lower-level creature, namely the eukaryotic cell, and how the eukaryotic cell itself, a symbiosis between two different cells, evolved out of prokaryotic ancestors. Hamilton's theory is the sole theory capable of explaining why they evolved (Bourke 2011; Maynard Smith and Szathmáry 1995; Okasha 2006).

There are three cellular domains: Archea and Eubacteria (together they form the prokaryotes), and the Eukaryota (animals, fungi and plants belong to this domain). There are many differences between the prokaryotes and the eukaryotes, but I shall only briefly discuss two of them. First, prokaryotes have a rigid outer cell wall, enabling them to live in water: it keeps them from swelling up and bursting like a balloon as water moves across the concentration gradient from the external medium to the cytoplasm. However, the cell wall has a disadvantage, for the cell can only feed off molecules that move through it. Eukaryotes do not have a cell wall but a cytoskeleton consisting of a network of protein filaments anchored to the cell membrane. This cytoskeleton stabilizes the cell from within like the steel girders of a modern building. The advantage is that the cell can predate on bacteria by engulfing them (i.e. by folding its membrane around them, i.e. by phagocytosis), for it has a flexible membrane at the outside. Second, the eukaryotic cell does, and the prokarytotic cell does not, have cell organelles. The point to notice is that cell organelles were originally free-living bacteria. One explanation of how bacteria became cell organelles (endosymbionts) is that in a proto-eukaryotic cell feeding on bacteria, some of the bacteria survived. If we assume that the encased bacteria provided the host cell with some useful molecules (as by-product of their metabolism), one can easily imagine the emergence of a cooperative (or symbiotic) relation between the host cell and the bacteria. Hence instead of digesting them, the bacteria were subsequently domesticated by the host cell and became cell organelles. Inclusive fitness theory explains the emergence of endosymbionts as the result of mutual benefit: the host cell and bacteria were genetically unrelated but cooperation was beneficial because different functions were combined in a new (higher-level) creature: the eukaryotic cell. 
For the origin of multicellularity inclusive fitness theory provides us with a different explanation. It is believed that the first step from independent cells to multicellular organisms was the formation of cell clusters. If we assume that these clusters consisted of cells that were genetically identical because the multicellular cluster was started from a single cell, then cooperation between the cells can be explained by kin selection (kin selection is part of inclusive fitness theory). Moreover, since the cells were identical, there were in small multicellular clusters no costs involved related to the suppression of cheaters. One can imagine that cells started to exchange molecules between them enhancing inclusive fitness. Cells could extend their cooperative interactions by producing ligands and receptors resulting in chemical communication: one cell could signal to another cell and alter its behaviour. Another important innovation was cell differentiation as the result of new mechanisms of gene regulation. When the differentiated cell state was also maintained during cell division (by, again, a new, epigenetic mechanism), specialized cells evolved which together with other cells could form organs that could execute different functions in the organism (e.g. heart or kidneys). The activities of these organs were regulated and coordinated resulting in different systems, e.g. the cardio-vascular system involved in the transport of oxygen and nutrients through the whole organism. Hence communications between cells resulted in a division of labour (epigenesis resulted in several organs executing different functions) and, subsequently, gave rise to organ systems, such as the immune system involved in the defence against pathogens, or the endocrine and nervous system regulating our metabolism and behaviour. From an evolutionary point of view, the relevant division of labour was the separation between nonreproductive somatic cells and the reproductive cells or gametes (see Michod 2007; West et al. 2015). This division of labour is explained by inclusive fitness theory in terms of altruism. Because the genes in somatic cells and gametes are identical $(\mathrm{r}=1)$, we can use kin selection for explaining why the altruistic behaviour of somatic cells evolved.

\section{Facilitated Evolution}

Fisher argued that lower-level exploratory behaviours are involved in the evolution of higher-level adaptations. I discuss in this section how lower-level exploratory behaviour facilitated the evolution of higher-level adaptations. I start again with the ideas of Lamarck because he too highlighted an important role of exploratory behaviour.

Lamarck, as we have seen above, advanced the idea that exploratory behaviour is the beginning of the evolution of adaptations. For example when some birds, as a result of their exploratory behaviour, started to forage on fish, their bill had to lengthen to reach the fish and their toes had to be stretched in order to create webbed feet. Over generations, this resulted according to Lamarck gradually in the required adaptations for their predatory behaviour (see Lamarck 1984 [1809], p. 119ff.). The point to notice is that in Lamarck's theory behavioural needs and wants drive the anatomy and physiology. Hence it is not changes in the shape, either of the body or 
its parts, which gives rise to the new habits of the birds, but it is the other way round: the habits, which are the result of aiming and striving (goal-directed action), lead in the end to changes in the shape (and physiology) of the body and of the parts of animals.

We know that these ideas of Lamarck are wrong for empirical reasons. Although there are adaptations occurring at the level of the somatic cells, these adaptations do not affect the gametes in a similar way, because the determinants in egg and sperm cells, as Weismann (1983 [1904], see also Smit 2010c) later argued against Lamarck, are not miniature somatic cells (e.g. muscle, skin, or nerve cells).

We can extend Fisher's alternative explanation of the origin of novelties by using the idea of facilitated evolution: a single, random mutation can have beneficial macroscopic effects for the cells that are affected by the mutation are embedded in a network or circuit of other cells (in which the mutation does not have an effect) that are capable of adjusting their activities and behaviour to the changes occurring in the mutated cell. Facilitated evolution means that mutations may lead to functional responses because they have effects in a microenvironment involving lower-level entities like cells and chemical reactions that are capable of displaying exploratory behaviour and can therefore contribute to the macroscopic adaptive response. I illustrate facilitated evolution by discussing an example taken from Kirschner and Gerhart (2005).

Recall that we (and the other animals) are able to adapt to changes in levels of oxygen. First, if our body is confronted by lower levels of oxygen (for example when we are running or are hiking in the mountains), then our body physiologically responds by an increase in the rate of breathing. Second, there is also a chemical mechanism that enables us to cope with lower levels of oxygen: the molecule that binds oxygen in our blood, haemoglobin, can adopt two configurations, and one of these can bind oxygen better. This enables our body, if necessary, to switch to more molecules with the configuration that binds oxygen better (increasing the level of oxygen in our blood). Third, there is also a cellular mechanism involved: if there are lower levels of oxygen, cells start to produce a growth factor (erythropoietin, better known as EPO because it was misused in blood doping for endurance sports like bicycling in order to improve performances) resulting in an increase in the number of red blood cells. And fourth, the body responds by the production of new blood capillaries. If there is not enough oxygen in a local environment (in a certain tissue of our body), then cells start to secrete a growth factor resulting in the production of a new capillary: it grows out of an already existing capillary in the direction from which the signal was released. That vessels are responsive to low levels of oxygen (hypoxia) was discovered in premature infants. When they were exposed to high levels of oxygen, they have reduced capillary growth. But when they were returned to normal oxygen conditions, the tissues that were previously oxygen-starved grew extraordinarily with disastrous consequences: for example their eyes leaked and bled, leading to scarring and to blindness.

The point to notice is that the fourth mechanism is also involved in the development of our vascular system (and during the development of the placenta). Blood vessels are formed in two ways: from specialized embryonic cells called angioblasts, and from existing blood vessels. In the early stages of development 
angioblasts coalesce and form hollow tubes, initiated by a growth factor. This step is highly deterministic and results in large vessels like the aorta and the major veins. But the development of smaller vessels (called angiogenesis) is partly on demand (as I have described above) and is not genetically pre-programmed. They sprout from already existing vessels. This depends on the local situation (oxygen level) in the tissues of the developing body. This is visible if we look at the different branches of the blood vessels just beneath the skin of our legs, arms or hands. There are always asymmetries here (e.g. between the left and right hand) which can be explained in terms of the on demand-process (explicable in terms of the integrated actions of lower-level cells).

For obvious reasons the 'on demand' system is adaptive, for it enables organisms to respond to damage: the processes are involved in wound healing and regeneration. But it requires no stretch of the imagination to see that these processes also enabled organisms to adapt to changes in the environment during our evolutionary history. Suppose that as a result of one mutation of genes in a cartilage cell (part of the skeleton) bones lengthen. This could result in the lengthening of a limb of which the bone is a part because of the on demand-system: the blood vessel system would automatically respond to the new situation by developing new vessels. A similar story can be told in the case of the development of muscle and nerve cells, for these cells, originating out of precursor cells present in the local environment, are also capable of responding to what is needed in the local situation. Muscle cells are formed in the trunk in clusters close to the nerve cord. They migrate from this site outward and follow an exploratory path closely linked to the developing blood vessel system. These precursor cells proliferate and differentiate then in response to local cues. Nerve cells also follow an exploratory path into the developing limb: cells extend their (long) axon and the axon tip by chance muscle cells. Since axons make multiple contacts with the muscle cells in the limbs, there is selection in favour of cells with the strongest signal. Thus changes in size or shape of the limb as the result of one mutation in a cell of the skeleton do not require new mutations of the cells involved in the developments of the capillaries, muscles and nervous system. The communication between cells in a multicellular organism results therefore in opportunities to 'create' changes at the macro-level (the circuits of interacting cells) as the result of one micro-mutation. ${ }^{7}$ In the webbing of the foot in birds that started to predate on fish a similar story can be told. The point to notice here is that the webbing of the bird's foot is a default state: the cells between the toes in birds that do not swim are later removed by cell suicide (apoptosis). We can easily imagine a mutation involved in apoptosis blocking the process of cell suicide, resulting in the webbed foot in birds that predate on fish.

These examples show that by noticing the exploratory behaviours of lower-level entities and how they are involved in the evolution of higher-level entities, we can explain how changes in morphological structures gradually resulted in new adaptations (note that this is the opposite of what Lamarck argued). This solves the problem of how simultaneous changes in the body are brought about in order to

\footnotetext{
${ }^{7}$ Mutations of genes involved in the regulation of the new macro-level structure can subsequently stabilize the change by bringing it under genetic control.
} 
establish function at the level of an aggregate (wing, hand, etc.) allowing selection to act on the novel structure. Note the difference with machines (and recall their role in the Cartesian conception of bodies). Suppose that we increase the number of cylinders of the car from four to six. Numerous other modifications are then necessary in order to make these cylinders functional. Importantly, without simultaneous modifications in the crankshaft, the oiling and cooling system, and the ignition system, the car would run poorly or would not run at all. In terms of mechanical evolution: there would be strong selection against this increase in the number of cylinders. Facilitated evolution shows why this is less of a problem in living creatures since the different types of cells display exploratory behaviour and which can, as the result of macroscopic selection, can be integrated in a higher-level system or circuitry.

\section{The Evolution of the Rational Psyche}

We have seen that Fisher highlighted the fact that natural selection results in active creatures that explore their environment. We have also seen that exploratory behaviour at lower levels (e.g. migration) facilitates the evolution of higher-level adaptations (e.g. the wing of a bird or the hand of a human). I shall discuss in this section how exploratory behaviour (displayed by our ancestors and the other animals) facilitated language evolution and, hence, the evolution of the human rational psyche.

Hamilton argued that there is exploratory, goal-directed behaviour discernable at all levels of organisation. Yet there are of course differences in the kind of goaldirected behaviours displayed by lower- and higher-level creatures. The point to notice is that evolutionary transitions resulted in an increase in life's complexity: new kinds of goal-directed behaviours evolved at higher levels of organisation, but also the repertoire of goal-directed behaviours expanded. The main problem we face when we study the evolution of the human rational psyche is what its precursors are, for only humans use a language. Moreover, the use of a language is a normative practice. I shall argue that we can solve this problem if we notice that the rulegoverned use of words evolved out of babbling (both during evolution and ontogenesis). For this answers the question what the precursors are and how out of babbling new (higher-level) adaptations could evolve.

Children are experimenters exploring their environment. They start to experiment with gestures and vocalizations from early on, i.e. during the second half of their first year. Children begin then to act upon objects around them by moving them at will and by bringing about changes in objects, e.g. by pushing and pulling them, touching them, or picking them up and handling them and, important for language development, by giving them to their parents. Because children are experimenters, observing is also to see what happens when one acts on objects. While they explore their environment, their vocalizing powers develop and this is at first interwoven with motor development and the development of gestural abilities (see among others Bates and Dick 2002; Iverson 2010). 
The changes occurring in their vocalizing powers are from babbling to canonical or reduplicated babbling to the use of words (Oller 2000). Importantly, babbling induces or invites socially guided vocal learning by parents, i.e. when children start to babble, their parents are inclined to join the activity children are at that moment engaged in and respond to their experimental activities and vocalizations with infant directed speech. Children begin then to respond to the cues and encouragement provided by their parents by improving their skills and vocal capacities. ${ }^{8}$

An important pattern in babbling is the serial pattern in the case of canonical babbling: the alternation of vowels and consonants. Note that this is also the basic pattern of words. Hence for understanding the evolution of speech it is essential to answer the question of what led to alternation of vowels and consonants. For if we understand the basic patterns of vowel-consonant alternation, we can explain how the use of more complex patterns was superimposed on these basic patterns resulting in the ability to do various things with words. MacNeilage (2008) has argued that the basic pattern of speech is the continual rhythmic alternation between an open and closed mouth imposed on the sound production process. The production of the first vowels (e.g. [a]) involves the opening of the mouth, whereas the production of the first consonants (e.g. [b]) involves the closing of the mouth. The assumption here is that during the early stages of language development the infant exerts independent control only of the jaw, while others articulators (lips, tongue and soft palate) had limited capacity to actively vary their position in the brief span of a syllable. For example during jaw oscillation, if the tongue is in its resting position, the elevating movements of the mandible will make the lips form a passive constriction and produce a labial consonant, while lowering the jaw produce a central vowel. When the ability to exert control on the articulators increased, variegation emerged (involving cortical regulation of speech ${ }^{9}$ ). Hence after the stage of reduplicated babbling the original reiterations ('Bababa') were replaced by utterances in which children produce for example different consonants and/or vowels in successive syllables (e.g. from 'Mamama' and 'Tototo' to 'Tomato').

It is possible that, during our evolutionary history, babbling had a signalling function, for example in the context of mother-child interaction (as an extension of motor patterns involved in sucking, licking, chewing) or in the context of grooming (it is presupposed here that babbling possibly evolved out of lip smacking). I suggest that the original small repertoire of signals extended as the result of an increase in vocal flexibility (involving the tongue and the lips) into a complex, combinatorial

\footnotetext{
${ }^{8}$ This requires vocal flexibility. Vocal flexibility, in contrast to flexibility of gesture, was probably limited in the early hominins. It evolved as the result of selection of variations of genes such as FOXP2 (because the product of this transcription factor is, among other things, involved in the control of fine orofacial movements, enabling the hominins to develop articulate speech; see Enard 2011) and coevolved with flexibility of gesture.

9 Since vocalizations (signals) in 'lower' animals are regulated by the midbrain (and, in part, by limbic structures), we only have to assume that, as the result of exploratory behaviour of cortical neurons (see Sect. 8), the articulators (jaw, lips, tongue) and the muscles of the larynx came under cortical control, resulting in an expansion of the volitional vocal powers displayed by the whole organism (see also Deacon 1997, chapter 8; Fitch 2010, chapter 9).
} 
system (assuming that the extension enhanced inclusive fitness). ${ }^{10} \mathrm{It}$ is assumed that good imitation skills and later more complex forms of learning were essential here. The crucial step in this scenario is that signals acquired in the end meaning, i.e. the signal 'mama' became then the spoken word for 'mother'. In terms of the theory advanced here: the signal became a spoken word when humans were able to do something with this utterance, e.g. as a call or exclamation ('Mama!') resulting in maternal attention. Not surprisingly, there was probably at first no sharp distinction between the first use of words and signals, because both were produced to draw (or direct) the attention of another (to something). Yet language development and evolution result in the transition to a normative practice, for children learn to use words correctly (this is further explained in Smit 2016). They learn what is to be done. A child can be said to have mastered the use of a word (say 'red') if his or her linguistic behaviour accords with the acknowledged rules for the correct employment of that word. For example a child understands what red is if he or she points to a ripe tomato for explaining the meaning of 'red', can correct mistakes of others and him- or herself, and so on and so forth. Whether a child possesses the ability to use words and sentences is determined by testing whether he or she (1) can use a language (e.g. words) correctly, (2) can explain its use correctly, and (3) responds appropriately to its use in context.

Because explanations of meaning remain within language, the pedagogical history (i.e. the gestures and vocalizations that were essential parts of the preceding forms of teaching and learning) dropped off. For a creature's pedagogical history is not a criterion for whether a creature has the ability to speak a language. We do not determine whether an alien is speaking a language or just emitting noise by investigating his past-we investigate what he can now do. Whether a child possesses this ability is determined by testing whether he can use a language correctly. To have acquired the ability to use a language, as Wittgenstein (2009 [1953], par. 150) put it, is to have mastered a technique, and the technique mastered is a normative one. Hence learning a language is important, but whether a child has mastered a language is only tested by the end product. Hence when language evolved from the first words to an expanded vocabulary with a grammar, it became irrelevant how someone has learnt a language.

Doing things with words is during ontogenesis and was during evolution expanded with reasoning and giving reasons (thinking; see Hacker 2013, chapter 10).

\footnotetext{
${ }^{10}$ Babbling and later linguistic behaviour possibly evolved when hominins started to wean children at earlier time (see Smit 2009, 2013). This became possible when they started to cooperate in the context of hunting large game (but also in the context of digging tubers, etc.). Food was (in the evolving huntergatherer societies) then present at a regular basis, enabling hominins to wean children at an earlier time, for humans could use protein-rich meat (but also plant food and tubers) as supplement to and alternative for maternal milk. Lactational anoestrus was therefore removed at an earlier age. The result was that hominins had a much shorter interbirth interval than the other apes, but also a longer juvenile dependence (nowadays, weaning occurs in natural fertility populations at about 1-4 years, while chimpanzees wean at 5 and orang-utans at 7.7 years). However, installing earlier weaning required several adaptations. For example 'tiny incisors' (milk teeth) evolved enabling children to consume solid food at an early age (milk teeth are absent in other apes). It also required behavioural adaptations enabling mothers and children to adjust their communicative behaviour to early weaning. I have suggested that babbling (but also gestures like pointing, etc.) and later linguistic behaviour evolved because these behaviours optimized the functioning of food provisioning in the family and group, and, hence, increased inclusive fitness.
} 
During ontogenesis this occurs when children, during their third and fourth year, acquire the ability to combine words; to describe, judge and assert something; to use a tensed language and logical connectives, quantifiers, personal pronouns, etc. Children acquire then the ability to reason, can think conditional thoughts, can think of how things are and how things are not, can conceive of general truths, can think of what does and what does not exist, can use modal expressions and counterfactuals, etc. Hence using a complex language enables children to think of possibilities (to imagine). They can think what would happen if ..., or what it would be like if ..., because they can imagine something differently and begin to understand that one can think falsely. Children can then express thoughts and beliefs and begin then to understand that others have thoughts and beliefs. This explains why developmental psychologists have found that children, who have mastered the use of a tensed language, et cetera, can solve false belief tasks at this age (although it is misguided to argue that they acquire then a Theory of Mind; see Smit 2010b).

Acquiring the ability to reason and to give reasons explains also why children then develop purposes beyond the immediate environment in space and time, since they can then express thoughts about the future and past. Hence there is a difference between the intentional behaviour of doers and thinkers, between simple and complex forms of heralding an intention. Simple forms are linked to acts like giving, taking, wanting, etc. In these cases forming and heralding an intention is linked to what children will do next ('Give toy' or 'Take toy' are followed by the act of giving or taking). Older children (3-4 years old) learn to extend these primitive forms of intentional actions with more complex ones when they have mastered the use of a tensed language, et cetera, enabling them to form long-term intentions (e.g. 'I'll see you next Wednesday' or 'I will return the toy I borrow from you next Wednesday'). The nexus between expressions of intentions and immediate performance weakens then: children acquire the skill to refer to entities outside the communication-situation, to talk about persons who are not present, to focus their attention on something unrelated to current needs and wishes, and so on and so forth. They have acquired the rational psyche.

\section{Conclusion}

I have discussed how we can extend the resolution of the mind-body problem of philosophers with its solution, by showing how we can integrate neo-Aristotelian monism with modern evolutionary theory so that we are able to construct and solve empirical problems. My discussion can be summarized in three key points.

First, for the resolution of the mind-body problem it is essential to return to Aristotelian monism, for this resolves the Cartesian problem of how the mind interacts with the body (or brain for that matter). The important point to notice is that Aristotle correctly noticed that there is no relation between the mind and body (as Cartesians assume). We can study the psyche by observing the expressions of the mental in the behaviour of living organisms, for the psyche is manifest in what organisms do and can do. 
Second, the contributions of Fisher and Hamilton explain how out of thermodynamic systems that have acquired heredity the three cellular domains evolved. We can discern several evolutionary transitions which we can study if we pay attention to how lower-level exploratory behaviour of entities facilitated the evolution of higher level structures that obtained new functions. This sheds new light on a conceptual observation already made by Aristotle, namely that we attribute psychological predicates to the whole, behaving organism, not to its parts (Hacker's mereological principle). I have discussed how facilitated evolution resulted in behaviours (e.g. displayed by multicellular organisms) which are emergent, higher-level adaptations. In Aristotelian terms: the vegetative and sensitive psyche evolved during the transition from unicellular to multicellular organisms (internal and external organs evolved in plants and self-moving animals). The rational psyche evolved as the result of another transition, namely the transition from animal signalling to linguistic communication. Just as the exploratory behaviour of cells made higher-level (emergent) structures, traits and functions of multicellular organisms possible, so too the exploratory behaviour of our (multicellular) ancestor made the evolution of the rational psyche possible. I have discussed how out of babbling first 'doing things with words' and later 'reasoning and giving reasons' evolved when our ancestors started to use word combinations, grammar and later judgments and inferences (when they started to use 'therefore', 'it follows', or 'so' to make chains of reasoning). Future studies will show how genetic variations, which only occur in humans, have altered the exploratory behaviour of cells in our nervous system in such way that higher-level adaptations could evolve (e.g. the evolution of volitional speech as the result of the altered behaviour of neurons involved in the cortical regulation of our speech apparatus, or the extension of experience-dependent learning as the result of an increase in brain plasticity). Hence we can predict that the evolution of the rational psyche was made possible by genetic variations involved in the expansion of our vocalizing powers and in socially guided learning (examples are discussed in Smit 2013, 2014). Notice that (an increase of) 'information-processing' in the brain or mind (as is assumed in cognitive neuroscience and evolutionary psychology) does not play any role in the explanation of language ontogenesis and evolution (and hence, does not explain why providing and seeking information in humans evolved), for there is no such thing as information-processing in the brain (or mind). The misguided idea that information-processing in the brain is essential for understanding language evolution can be traced back to the Cartesian conception extended with (an incorrect interpretation of) Darwin's theory (see Bennett and Hacker 2006, 2015; Smit 2011, 2014).

Third, Fisher, Hamilton and others have argued that, although language evolution resulted in the rational psyche, language evolution did not result in a new biological entity. Yet it was a transition since it led to new ways of communicating. Notice again the difference with the Cartesian conception: doing things with words and later reasoning and giving reasons are not brought about by the activity of alleged entities as the immaterial Self (Descartes) or the material brain (many contemporary neuroscientists and evolutionary psychologists). There is no such thing as a separate entity (mind, brain) causing linguistic, volitional acts (and it does not receive 
linguistic information). We are composed of integrated parts which evolved as the result of evolutionary transitions, but it is the (whole) agent that acts and takes action, seeks and provides information, not its mind or brain. Hamilton's inclusive fitness theory teaches us that we (as agents) consist of cooperative parts that are functionally integrated and have traits not present at lower levels.

The expansion of our vocalizing powers resulted in the evolution of the human rational psyche. But when complex language games evolved enabling humans to reason and to give reasons, the constraints of genetic evolution were removed: natural evolution was in part replaced by cultural evolution. Hence the theory discussed in this paper clarifies why the many genes that are unique to humans are involved in the transition from nature to culture: they do no longer cause us to act, but became progressively involved in brain processes that enable us to act ${ }^{11}$ (brain processes became a causal condition). As the result of language evolution the capacity to pursue self-selected goals expanded and this became, in Fisher's words, the crowning stage of natural evolution. Yet because the rules for the use of words and sentences (grammar) are autonomous (they are not grounded in nature or human nature), they only support each other resulting in a free-floating network of concepts. Intentional behaviour, made possible by language evolution, was therefore not only the crowning stage of natural evolution, but also marked the shift from natural to cultural evolution resulting in religion, technology, science, etc. This part of our journey is therefore better explained, not by evolution, but by our history.

Acknowledgements I am grateful to Peter Hacker for his comments on an earlier draft of this paper and thank two reviewers for their helpful comments.

Open Access This article is distributed under the terms of the Creative Commons Attribution 4.0 International License (http://creativecommons.org/licenses/by/4.0/), which permits unrestricted use, distribution, and reproduction in any medium, provided you give appropriate credit to the original author(s) and the source, provide a link to the Creative Commons license, and indicate if changes were made.

\section{References}

Ataman, B., Boulting, G. L., Harmin, D. A., Yang, M. G., Baker-Salisbury, M., Yap, E. L., et al. (2016). Evolution of Osteocrin as an activity-regulated factor in the primate brain. Nature, 539, 242-246.

Bates, E., \& Dick, F. (2002). Language, gesture, and the developing brain. Developmental Psychobiology, 40, 293-310.

Bennett, M. R., \& Hacker, P. M. S. (2003). Philosophical foundations of neuroscience. Oxford: Blackwell Publishing.

Bennett, M. R., \& Hacker, P. M. S. (2006). Language and cortical function: Conceptual developments. Progress in Neurobiology, 80, 20-52.

\footnotetext{
${ }^{11}$ It is interesting to see that the gene Ostn, coding for osteocrin, is in humans (it has a similar function in primates and the other apes) expressed in the neocortex and is involved in experiential learning, but in 'lower' mammals expressed in muscles and bones (not in the brain) and is then involved glucose metabolism. The gene obtained this new function as the result of mutations modifying the promoter region of the gene so that it can respond to transcription factors involved in activity-dependent transcription in neurons (see Ataman et al. 2016).
} 
Bennett, M. R., \& Hacker, P. M. S. (2015). On explaining and understanding cognitive behaviour. Australian Journal of Psychology, 67, 241-250.

Bourke, A. F. G. (2011). Principles of social evolution. Oxford: Oxford University Press.

Chalmers, D. (1996). The conscious mind. Oxford: Oxford University Press.

Csibra, G., \& Gergely, G. (2006). Social learning and social cognition: The case for pedagogy. In Y. Munakata \& M. H. Johnson (Eds.), Processes of change in brain and cognitive development (pp. 249-274). Oxford: Oxford University Press.

Csibra, G., \& Gergely, G. (2009). Natural pedagogy. Trends in Cognitive Science, 13, 148-153.

Davies, N. B., Krebs, J., \& West, S. A. (2012). An introduction to behavioural ecology. Oxford: WileyBlackwell; Fourth edition.

Deacon, T. W. (1997). The symbolic species; The co-evolution of language and the brain. New York: W.W. Norton \& Company.

Enard, W. (2011). FOXP2 and the role of cortico-basal ganglia circuits in speech and language evolution. Current Opinion in Neurobiology, 21, 415-424.

Evans, V. (2014). The language myth; Why language is not an instinct. Cambridge: Cambridge University Press.

Fisher, R. (1930). The genetical theory of natural selection. Oxford: Oxford University Press.

Fisher, R. A. (1934). Indeterminism and natural selection. Philosophy of Science, 1, 99-117.

Fisher, R. A. (1950). Creative aspects of natural law. Cambridge: Cambridge University Press.

Fitch, W. T. (2010). The evolution of language. Cambridge: Cambridge University Press.

Gardner, A., West, S. A., \& Wild, G. (2011). The genetical theory of kin selection. Journal of Evolutionary Biology, 24, 1020-1043.

Hacker, P. M. S. (1990a). Wittgenstein: Meaning and mind. Oxford: Basil Blackwell.

Hacker, P. M. S. (1990b). Chomsky's problems. Language \& Communication, 10, 127-148.

Hacker, P. M. S. (1996). Wittgenstein: Mind and will; Part 1: Essays. Oxford: Basil Blackwell.

Hacker, P. M. S. (2002). Is there anything it is like to be a bat? Philosophy, 77, 157-174.

Hacker, P. M. S. (2007). Human nature; The categorial framework. Oxford: Basil Blackwell.

Hacker, P. M. S. (2013). The intellectual powers: A study of human nature. Chichester: Wiley-Blackwell.

Hamilton, W. D. (1964). The genetical theory of social behaviour I and II. Journal of Theoretical Biology, 7, $1-52$.

Iverson, J. M. (2010). Developing language in a developing body: The relationship between motor development and language development. Journal of Child Language, 37, 229-261.

Johannsen, W. (1910). The genotype conception of heredity. American Naturalist, 45, 129-159.

Kenny, A. (1984). The legacy of wittgenstein. Oxford: Basil Blackwell, Oxford.

Kenny, A. (1988). Cosmological explanation and understanding. In L. Herzberg \& J. Pietarinen (Eds.), Perspectives on human conduct (pp. 72-87). Leiden: Brill.

Kenny, A. (1989). The metaphysics of mind. London: Clarendon Press.

Kirkwood, T. B. L. (1977). Evolution of aging. Nature, 270, 301-304.

Kirschner, M., \& Gerhart, J. C. (2005). The plausibility of life; Resolving Darwin's Dilemma. New Haven: Yale University Press.

Köhler, W. (1947). Gestalt psychology; An introduction to new concepts and modern psychology (2nd ed.). New York: Liveright Publishing Corporation.

Lamarck, J.B. (1984 [1809]). Zoological philosophy; An exposition with regard to the natural history of animals. Chicago: University of Chicago Press. Translated by H. Elliot.

MacNeilage, P. F. (2008). The origin of speech. Oxford: Oxford University Press.

Malcolm, N. (1986). Wittgenstein: Nothing is hidden. Oxford: Basil Blackwell.

Maynard Smith, J., \& Szathmáry, E. (1995). The major transitions in evolution. New York: W.H. Freeman.

Michod, R. E. (2007). Evolution of individuality during the transition from unicellular to multicellular life. Proceedings of the National Academy of Sciences of the USA, 104(suppl. 1), 8613-8618.

Nagel, T. (1974). What is it like to be a bat? Philosophical Review, 83, 435-450.

Okasha, S. (2006). Evolution and the levels of selection. Oxford: Oxford University Press.

Oller, D. K. (2000). The emergence of the speech capacity. Mahwah, NJ: Lawrence Erlbaum Associates.

Pinker, S. (1995). The language instinct: How the mind creates language. New York: Harper Collins Perennial.

Smit, H. (2009). Genomic imprinting and communicative behaviour; Prader-Willi and Angelman syndrome. Netherland Journal of Psychology, 65, 78-88. 
Smit, H. (2010a). Darwin's rehabilitation of teleology versus Williams' replacement of teleology by natural selection. Biological Theory, 5, 357-365.

Smit, H. (2010b). A conceptual contribution to battles in the brain. Biology and Philosophy, 25, 803-821.

Smit, H. (2010c). Weismann, Wittgenstein and the homunculus fallacy. Studies in the History and Philosophy of Biology and the Biomedical Sciences, 41, 263-271.

Smit, H. (2011). Conflicts in our mind. Theory and Psychology, 21, 377-395.

Smit, H. (2013). Effects of imprinted genes on the development of communicative behavior; A hypothesis. Biological Theory, 7, 247-255.

Smit, H. (2014). The social evolution of human nature: From biology to language. Cambridge: Cambridge University Press.

Smit, H. (2016). The transition from animal to linguistic communication. Biological Theory, 11, 158-172.

Smit, H., \& Hacker, P. M. S. (2014). Seven misconceptions about the mereological fallacy: A compilation for the perplexed. Erkenntnis, 79, 1077-1097.

Weismann, A. (1983 [1904]). The Theory of Evolution, two volumes. New York: AMS Press. Translation by J.A, Thomson and M.R. Thomson. German title: Vorträge über Descendenztheorie.

West, S. A., Fisher, R. M., Gardner, A., \& Kiers, E. T. (2015). Major evolutionary transitions in individuality. Proceedings of the National Academy of Sciences of the USA, 112, 10112-10119.

West, S., \& Gardner, A. (2013). Adaptation and inclusive fitness. Current Biology, 23, R577-R584.

White, A. R. (1967). The philosophy of mind. New York: Random House.

Williams, G. C. (1985). A defense of reductionism in evolutionary biology. In R. Dawkins \& M. Ridley (Eds.), Oxford surveys in evolutionary biology (pp. 1-17). Oxford: Oxford University Press.

Wittgenstein, L. (2009 [1953]). Philosophical Investigations. Translated by G.E.M. Anscombe, P.M.S. Hacker and J. Schulte. Revised fourth edition by P.M.S. Hacker and J. Schulte. Chichester: WileyBlackwell. 